\title{
COMPETÊNCIA EM INFORMAÇÃO PARA A IGUALDADE RACIAL
}

\author{
Gleyce Kelly Alves Sousa ${ }^{1}$ \\ Universidade Federal de Goiás \\ gleycinhakellyas@gmail.com \\ Erinaldo Dias Valério ${ }^{2}$ \\ Universidade Federal de Goiás \\ erinaldodiasufc@yahoo.br \\ Arthur Ferreira Campos ${ }^{3}$ \\ Universidade Federal da Paraíba \\ arthurfcampos94@gmail.com
}

\begin{abstract}
Resumo: Informa que a competência em informação são habilidades que o sujeito exerce para o uso, a busca e a avaliação da informação. Discute sobre a competência em informação, no campo das relações raciais, das (os) estudantes da Faculdade de Informação e Comunicação na Universidade Federal de Goiás, a fim de colaborar com a agenda antirracista. Realiza pesquisa básica, exploratória e bibliográfica, com abordagem qualitativa. Utiliza como instrumento de coleta de dados questionário, aplicado via Google Forms. Aponta que as (os) discentes necessitam de uma formação mais pontual que possibilite uma discussão sobre a situação da população negra brasileira e o entendimento sobre as relações raciais no Brasil. Conclui que a competência em informação é importante para a (o) futura (o) profissional da informação e comunicação no debate das relações raciais para a promoção da igualdade racial, buscando orientar a sociedade para a igualdade racial.
\end{abstract}

Palavras-chave: Competência em informação. Relações raciais - população negra. Profissional da informação e comunicação.

\section{INFORMATION LITERACY FOR RACIAL EQUALITY}

\begin{abstract}
Informs that information literacy are skills that the subject exercises for the use, search and evaluation of information. Discusses the information literacy, in the field of race relations, of students from the Faculdade de Informação e Comunicação da Universidade Federal de Goiás, in order to collaborate with the anti-racist agenda. Performs basic, exploratory and a bibliographic research, with the qualitative approach. It uses a questionnaire data collection tool, applied via Google Forms. It points out that the students need a more punctual training that allows a discussion about the situation of the black Brazilian population and the understanding of race theme in Brazil. It concludes that the information literacy is important for the future professional of the information and communication in the debate of the racial relations for the promotion of the racial equality, seeking to orient the society towards the racial equality.
\end{abstract}

Keywords: Information Literacy. Racial Relations - black population. Information and Communication Professional.

\footnotetext{
${ }^{1}$ Bacharela em Biblioteconomia pela Faculdade de Informação e Comunicação da Universidade Federal de Goiás.

2 Doutor em Ciência da Informação pelo Programa de Pós-Graduação em Ciência da Informação da Universidade Federal do Rio de Janeiro e do Instituto Brasileiro de Informação em Ciência e Tecnologia (PPGCI/IBICT-UFRJ). Mestre em Ciência da Informação pela Universidade Federal de Pernambuco (PPGCI/UFPE) e Graduação em Biblioteconomia pela Universidade Federal do Ceará (UFC/Campus Cariri). Professor da Faculdade de Informação e Comunicação da Universidade Federal de Goiás (FIC/UFG).

${ }^{3}$ Doutorando em Ciência da Informação (PPGCI/UFPB). Mestre em Ciência da Informação pela Universidade Federal da Paraíba (UFPB). Bacharel em Biblioteconomia (UFRN). Graduando em Arquivologia (UFPB).
} 


\section{INTRODUÇÃO}

Os estudos sobre as relações raciais no Brasil contribuem para disseminar informações sobre populações historicamente discriminadas, denunciando e combatendo as práticas racistas. Podemos inferir que as (os) profissionais da informação e comunicação, por falta de competência em informação, podem reproduzir comportamentos racistas em seus ambientes de atuação e, consequentemente, na prática social. Portanto, analisar a competência em informação desse grupo, a partir de seus conhecimentos na busca e no uso da informação, é necessário para o enfrentamento de preconceitos, da discriminação e do racismo que afetam a população negra.

O (a) profissional enquanto mediador (a) de informações precisa ser capacitado(a) no que diz respeito às ferramentas para o acesso a fontes de informação específicas, conhecendo os direitos conquistados pela população negra, intensificando a representatividade e em prol de uma sociedade antirracista. Atualmente, no Brasil, o compartilhamento de informações falsas tem refletido a falta de competência em informação da população, portanto pensamos que profissionais que atuam nas áreas da informação e comunicação podem realizar um trabalho educativo nesse contexto.

A Universidade, enquanto locus para a educação e construção de conhecimento, pode contribuir com o processo educacional e cultural das (dos) futuras (os) profissionais que irão se inserir no mercado de trabalho. Sendo assim, é necessário que essa instituição colabore para o enfrentamento do racismo, inserindo no mercado ações e inciativas que possam auxiliar esse processo.

A partir desse ensejo, temos o questionamento: as (os) discentes dos cursos de Biblioteconomia, Gestão da Informação, Jornalismo, Publicidade e Propaganda e Relações Públicas da Faculdade de Informação e Comunicação (FIC) da Universidade Federal de Goiás (UFG), possuem competência em informação para atuarem no campo das relações raciais em prol da igualdade racial? Para responder a esta pergunta, objetiva analisar a competência em informação no campo das relações raciais, com foco na população negra, das (os) estudantes da FIC/UFG. Para tanto, foi realizada uma pesquisa bibliográfica, exploratória com a aplicação de questionário para recolher depoimentos dessas (es) discentes e atender o objetivo proposto. 


\section{APONTAMENTOS SOBRE A COMPETÊNCIA EM INFORMAÇÃO}

Competência em informação é a habilidade ou conjunto de habilidades que determinam a seleção de informação de qualidade, o uso de fontes de informação, buscas, tendo o sujeito a capacidade de filtrar e analisar conteúdos. A competência em informação pode ser adquirida no âmbito do curso da graduação (bacharelado ou licenciatura).

De acordo com Gasque (2010), as habilidades adquiridas através da competência em informação colaboram com o acesso a informação, visto que essas habilidades permitem o planejamento de estratégias de busca e recuperação da informação. É necessário avaliar estratégias referentes ao uso do sistema de recuperação da informação, articulando a competência e as habilidades informacionais.

O sujeito competente em informação busca e manuseia a informação procurando se adaptar ao fluxo informacional, filtrando conteúdos e colaborando com o processo de aprendizado. Desse modo, a competência colabora com a eficiência de se compartilhar informação para um grupo, comunidade ou nação. O termo competência informacional também é utilizado na literatura científica e, no processo de recuperação de informação mediante a pesquisa bibliográfica realizada, foram encontrados materiais utilizando esse termo. Em contrapartida, neste artigo, é trabalhado o termo competência em informação.

De acordo com Peres (2011), a informação é necessária nos campos das relações pessoais, sociais e organizacionais, em quantidade e velocidade que trazem comodidade ao sujeito. Com os avanços tecnológicos crescendo exponencialmente, a busca por informação de qualidade torna-se uma importante habilidade para a eficiência do trabalho da (o) profissional da informação e comunicação. Essa (e) profissional pode entregar para a sociedade um trabalho de mediação em relação ao uso das Tecnologias de Informação e Comunicação.

\footnotetext{
Assim sendo, tem-se que a competência em informação conecta-se com as experiências solidárias e coletivas vivenciadas nas dinâmicas de aprendizagem continuada a partir de uma perspectiva ética e crítica, o que exige o acesso, a avaliação e o uso da informação de forma responsável, interdependente e colaborativa (ZATTAR, 2017, p. 287).
}

A competência em informação tem como base a obtenção de conhecimento por meio da busca, avaliação e do uso da informação, cooperando com o aprendizado. Apesar da facilidade propiciada pelos recursos tecnológicos, grandes são os problemas referentes à quantidade e a velocidade de circulação da informação, que proporcionam impactos negativos na sociedade, valorizando apenas alguns sujeitos e excluindo outros (PIRES, 2012). 


\subsection{DIMENSÕES DA COMPETÊNCIA EM INFORMAÇÃO}

A competência em informação trabalha com as dimensões técnica, estética, política e ética (VITORINO; PIANTOLA, 2011). O Quadro 1 demonstra essas dimensões segundo as autoras.

Quadro 1 - Dimensões da competência em informação

\begin{tabular}{|c|c|c|c|}
\hline Dimensão técnica & Dimensão estética & Dimensão ética & Dimensão política \\
\hline $\begin{array}{l}\text { Meio de ação no } \\
\text { contexto da } \\
\text { informação. }\end{array}$ & Criatividade sensível. & $\begin{array}{l}\text { Uso responsável da } \\
\text { informação. }\end{array}$ & $\begin{array}{l}\text { Exercício da } \\
\text { cidadania }\end{array}$ \\
\hline $\begin{array}{c}\text { Consiste nas } \\
\text { habilidades } \\
\text { adquiridas para } \\
\text { encontrar, avaliar e } \\
\text { usar a informação de } \\
\text { que precisamos. }\end{array}$ & $\begin{array}{l}\text { Capacidade de } \\
\text { compreender, } \\
\text { relacionar, ordenar, } \\
\text { configurar e } \\
\text { ressignificar a } \\
\text { informação. }\end{array}$ & $\begin{array}{l}\text { Visa à realização do } \\
\text { bem comum. }\end{array}$ & $\begin{array}{l}\text { Participação dos } \\
\text { indivíduos nas } \\
\text { decisões e nas } \\
\text { transformações } \\
\text { referentes à vida } \\
\text { social. } \\
\end{array}$ \\
\hline \multirow{2}{*}{$\begin{array}{l}\text { Ligada à ideia de que } \\
\text { o indivíduo } \\
\text { competente em } \\
\text { informação é aquele } \\
\text { capaz de acessar com } \\
\text { sucesso e dominar as } \\
\text { novas tecnologias. }\end{array}$} & \multirow{2}{*}{$\begin{array}{l}\text { Experiência interior, } \\
\text { individual e única do } \\
\text { sujeito ao lidar com } \\
\text { os conteúdos de } \\
\text { informação e sua } \\
\text { maneira de expressá- } \\
\text { la e agir sobre ela no } \\
\text { âmbito coletivo. }\end{array}$} & \multirow{2}{*}{$\begin{array}{c}\text { Relaciona-se a } \\
\text { questões de } \\
\text { apropriação e uso da } \\
\text { informação, tais } \\
\text { como propriedade } \\
\text { intelectual, direitos } \\
\text { autorais, acesso à } \\
\text { informação e } \\
\text { preservação da } \\
\text { memória do mundo. }\end{array}$} & $\begin{array}{l}\text { Capacidade de ver } \\
\text { além da superfície do } \\
\text { discurso. }\end{array}$ \\
\hline & & & $\begin{array}{c}\text { Considera que a } \\
\text { informação é } \\
\text { produzida a partir de } \\
\text { (e em) um contexto } \\
\text { específico. }\end{array}$ \\
\hline
\end{tabular}

Fonte: Extraído de Vitorino e Piantola (2011, p. 109).

A dimensão técnica é indicada para a utilização prática do uso e da busca para acesso ao conhecimento. De acordo com Rios (2006), se refere à atividade prática que resulta em informação, em que o sujeito competente em informação consegue utilizar, manipular e dominar meios, avaliando a informação buscada.

A dimensão estética abrange os meios criativos e sensíveis. Para Rios (2006), se refere à capacidade de compreender as informações encontradas, de maneira que se possa colaborar com a manifestação do seu saber. A dimensão ética diz respeito ao modo como são utilizadas às informações. Abrange o uso responsável no contexto da busca e do uso da informação, de maneira que possam cooperar com as leis de acesso e os valores quanto ao uso da informação (RIOS, 2006).

A dimensão política é o modo como as (os) cidadãs (ãos) se posicionam perante as informações relacionadas à cidadania. De acordo com Rios (2006), está relacionada às leis e normas, contribuindo para que os indivíduos conheçam seus direitos e deveres. Nesse 
contexto, inserimos os estudos em competência em informação relacionados ao campo das relações raciais.

\section{UMA ABORDAGEM SOBRE AS RELAÇÕES RACIAIS}

Socialmente, o termo raça é usado para classificar os seres humanos de acordo com um grupo de pessoas. Munanga (2003) salienta que o conceito de raça significa sorte, categoria ou espécie. Para Paixão e Carvalho (2008), o termo raça primeiramente dialoga com os termos físicos, isto é, a aparência, levando em conta o grau de pigmentação da pele, os fenótipos faciais, as cores dos olhos, o formato do cabelo e o pertencimento cultural.

Munanga (2003) apresenta que a cor da pele foi um fator de divisão entre as raças, dividindo-se entre três raças: branca, negra e amarela, onde a cor da pele é definida pela concentração da melanina. A raça é determinada pelos sistemas classificatórios, mais sociais do que biológicos, que determinam o lugar de cada indivíduo na sociedade, cooperando com a identificação do ser humano.

A raça era discutida como fator biológico e hoje é considerada como fator social. De acordo com Guimarães (2008), a construção da raça é cientificamente social e não biológica, ao tratar das igualdades raciais. De acordo com Silvério (2002), no Brasil há diversos argumentos que desqualificam os movimentos negros e que buscam a implementação de políticas compensatórias alegando que os movimentos negros e a visibilidade racial não são necessários haja vista que o Brasil é um país em que a maior parte da população é mestiça.

Theodoro (2014) ressalta que a ideia de um Brasil visto como uma democracia racial, difundida no discurso de convivência harmoniosa entre pessoas de todas as raças, credos e culturas surgiu a partir da ditadura militar, que pregava que a discriminação racial não existia e que, por isso, não havia a necessidade de se adotar políticas para assegurar a igualdade racial. Ainda, conforme Theodoro (2014), a sociedade brasileira convive com o racismo, com a persistência da desigualdade racial advinda da pobreza, com o acúmulo de carência e da falta de estudo e saúde precária vivenciada pela população negra. O racismo é a segregação de um grupo, diferenciado por seus traços culturais, físicos, intelectuais e religiosos, tratados de maneira inferior, onde não há a aceitação da diversidade humana. Atualmente o racismo gera desigualdade e violência através da cor da pele, os traços físicos, suas diferenças na religião entre outros aspectos (ALMEIDA, 2018).

Nesse contexto, a visibilidade da população negra e o acesso a informação étnicoracial contribui para as práticas antirracistas. $\mathrm{O}$ (a) profissional da informação e comunicação 
competente em informação pode atuar também na luta antirracista. A disseminação da informação é um grande fator para a luta contra o racismo no Brasil, o que torna essencial a presença de discussões relativas à temática racial nas Universidades, escolas, centros de informação, entre outros.

Como responsável pelo desenvolvimento de ações antirracistas, o movimento negro busca estabelecer a igualdade racial. Valério e Silva (2018, p. 180) evidenciam que esse movimento "tem produzido informações em diversos suportes que contemplam a realidade e necessidade de ações inclusivas que reduzem os conflitos raciais". Desse modo, devem ser analisados todos os fatores para que as (os) futuras (os) profissionais colaborem nesse processo, oferecendo conhecimento referente às práticas do racismo e como combatê-las.

[...] O uso do conceito parte da concepção da perspectiva positiva e afirmativa de vida, no sentido de reconhecimento da história e existência, com foco nas culturas africanas. Pode-se inferir que se localizam aí os estudos que possam contribuir para acabar com os preconceitos e as atitudes forjadas nas ideologias do racismo contra populações discriminadas. E, nesse contexto, se insere a informação étnico-racial. (VALÉRIO; SILVA, 2018, p. $185)$.

Entendemos que no contexto da FIC/UFG, o (a) profissional da informação e comunicação pode colaborar de maneira eficiente em relação ao enfrentamento do racismo, propondo a criação de ações afirmativas dentro de suas áreas de atuação.

\section{PROCEDIMENTOS METODOLÓGICOS}

A pesquisa é o meio pelo qual se procura informações respondendo inquietações individuais ou coletivas, através de procedimentos sistemáticos (GIL, 2008). Segundo Prodanov e Freitas (2013), a pesquisa contribui para a consciência crítica da (o) pesquisadora (or), analisar os dados necessários, trazendo eficiência aos resultados. Neste artigo, buscam-se os resultados para a análise da competência em informação das (os) discentes da FIC/UFG na agenda antirracista, tendo como amostra as (os) alunas (os) dos cinco cursos: Biblioteconomia, Gestão da Informação, Jornalismo, Publicidade e Propaganda e Relações Públicas.

A natureza é básica, com abordagem qualitativa. Quanto aos objetivos, é exploratória, que para Gil (2008, p. 41), "têm como objetivo principal o aprimoramento de ideias ou a descoberta de intuições", realizando levantamentos bibliográficos, coleta de dados. 
Investigou-se a competência em informação, construindo conhecimento para cooperar com as práticas da agenda antirracista.

\subsection{INSTRUMENTO DE COLETA DE DADOS E AMBIENTE DA PESQUISA}

O instrumento para coleta de dados se deu através do envio por e-mail de um questionário eletrônico, via Google Forms, com 17 perguntas: 15 fechadas e duas abertas, enfatizando o debate sobre o racismo e procurando sugestões sobre como as (os) futuras (os) profissionais da informação e comunicação (respondentes) poderiam colaborar com a agenda antirracista. Tivemos o retorno de 137 discentes oriundas (os) dos cinco cursos da FIC/UFG: 55 alunas (os) de Biblioteconomia, 23 de Gestão da informação, 20 de Jornalismo, 11 de Publicidade e Propaganda e 28 de Relações Públicas.

\section{COLETA E ANÁLISE DE DADOS}

As análises estão divididas em dois blocos, em que o primeiro se refere às perguntas fechadas e o segundo às perguntas abertas. É importante ressaltar que o questionário foi disponibilizado via eletrônica, na plataforma do Google Forms.

\subsection{BLOCO 1: ANÁLISE DAS PERGUNTAS FECHADAS}

A amostra alcançada foi composta por $40,4 \%$ discentes do curso de Biblioteconomia, estando em maioria; 20,6\% de discentes do curso de Relações Públicas; 16,9\% de discentes do curso de Gestão da Informação; $14 \%$ de discentes do curso de Jornalismo e 8,1\% de discentes do curso de Publicidade e Propaganda.

Quanto a identidade de gênero, 63,2\% se consideram mulher cis, 33,1\% se consideram homem cis, 2,2\% preferiram não opinar e 1,5\% assinalaram a alternativa "outros". Quanto a faixa etária, 74,3\% dos respondentes, estão entre 19 à 25 anos; 19,9\% estão entre 26 à 35 anos; 2,9\% possuem mais de 46 anos; 1,5\% estão entre 36 à 45 anos; e 1,5\% possuem menos de 18 anos. Percebemos então que de 137 respostas, 101 sujeitos estão entre 19 à 25 anos.

Quanto a raça/cor da pele, $45,6 \%$ dos sujeitos se reconhecem como brancos, $37,5 \%$ se reconhecem como pardos, $15,4 \%$ se reconhecem como pretos e $1,5 \%$ se reconhecem como amarelos. Não houve nenhum sujeito reconhecendo-se como indígena. O conceito de raça é significativo por diversos fatores, pois aborda a caracterização do indivíduo na sociedade. Munanga (2003) frisa que o conceito de raça não deve ser biológico, pois tem ideologia, 
mesmo que existam categorias distintas, mas deve ser determinado pela estrutura global da sociedade e pelas relações de poder do governo.

Como já apontado por Munanga (2003), a cor da pele foi um dos critérios para a raça, tornando a espécie humana dividida em três raças: amarela, branca e negra (incluindo pretos e pardos). Sendo assim, 52,5\% das (os) discentes participantes fazem parte da população negra brasileira. É notório que há mais sujeitos se inserindo como brancos e pardos e poucos como negros.

Quanto a busca em fontes de informação, 98,5\% da amostra realizam suas buscas pela internet; 62,5\% utilizam livros como fonte de informação; 27,2\% utilizam revistas especializadas; $8,8 \%$ realizam buscas por enciclopédias; $18,4 \%$ realizam buscas por meio de dicionários; e 12,5\% buscam informações em outros mecanismos de busca. No contexto da competência em informação, é necessário utilizar fontes de informações confiáveis, baseadas no uso de ferramentas sérias e que compartilhem informações verossímeis. Araújo e Fachin (2015) dizem que fonte de informação pode ser qualquer documento, link, fotografia ou outra ferramenta que tem como característica informar alguém.

De acordo com Araújo e Fachin (2015), as fontes de informação permitem criar, recriar e ter acesso ao conhecimento sobre qualquer assunto e área de interesse ou pesquisa. Com o avanço da internet e da web social, as trocas de informação e conhecimento perpassam de maneira digital. Quanto a utilização da biblioteca, 85,3\% das (os) discentes responderam que frequentam a Biblioteca Central da Universidade Federal de Goiás - campus Samambaia e 14,7\% não a frequentam. Ainda é preocupante o fato de que, em uma Universidade, existam sujeitos que não frequentem essa unidade de informação. Ressaltamos que a biblioteca, sendo detentora e disseminadora de informação, contribui para o processo de busca e uso da informação.

Investigamos que cerca de $55,1 \%$ das (os) respondentes frequentam a biblioteca eventualmente; $22,0 \%$ a visitam uma vez na semana; $11,9 \%$ a visitam uma vez a cada mês e $11 \%$ visitam a biblioteca a cada quinze dias. Para consulta de material, 23,7\% realizam consultas rápidas; 44,1\% utilizam as salas de estudo individual; 47,8\% a frequentam para pesquisas em geral; 23,5\% a frequentam para estudos em grupos; 72,1\% para empréstimos e devoluções de materiais; $16,9 \%$ a utilizam para frequentar eventos e 10,3\% responderam a opção de outros tipos de acesso. Constatamos que a maioria dos sujeitos visitam a biblioteca para empréstimo e devolução, pesquisas e estudo individual. O Gráfico 1 aponta como as (os) discentes buscam por materiais na biblioteca. 
Gráfico 1 - Quando as (os) discentes utilizam os materiais

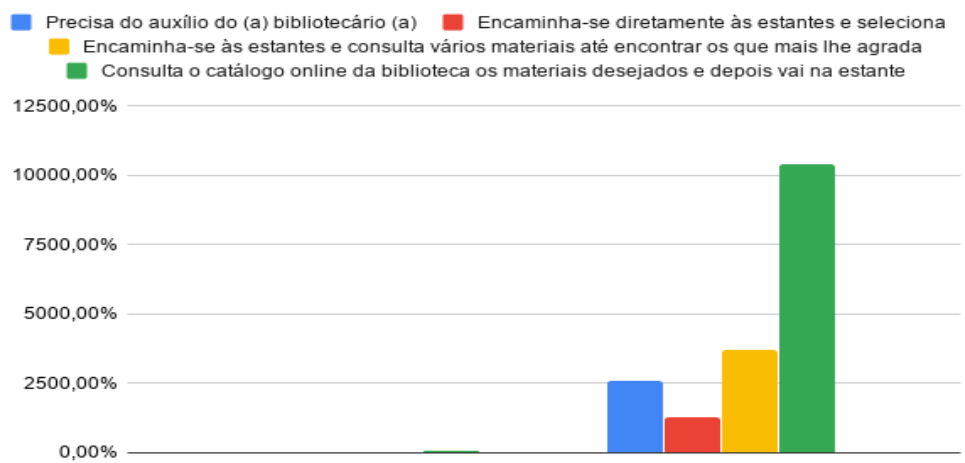

Fonte: Dados da pesquisa (2019).

De acordo com as respostas obtidas, quando os sujeitos da amostra utilizam a biblioteca: 20,2\% que a frequentam precisam do auxílio do (a) bibliotecário (a); 10,1\% se encaminham diretamente para as estantes e selecionam o que necessitam; 28,7\% encaminham-se às estantes checando vários materiais até encontrar os que mais respondem a necessidade de informação; e 80,6\% consultam no catálogo online da biblioteca os materiais desejados e depois vão até a estante buscar o material.

De acordo com Bastos (2013), o serviço de referência representa a ligação entre a (o) leitora (or) e a necessidade de economizar tempo para procurar determinada informação. É essencial compreender o papel fundamental da (o) bibliotecária (o) e a importância da biblioteca em âmbito de seu papel social possibilitado pela construção de conhecimento. Ainda em referência a Bastos (2013), o serviço de referência pode se tornar um dos mais importantes recursos que a biblioteca pode oferecer para a (o) leitora (or), mas muitas (os) usuárias (os) não o utilizam por desconhecer tal serviço ou pela falta de cometência da (o) profissional do setor. O Gráfico 2 apresenta a satisfação mediante o uso das informações dispostas na biblioteca.

Gráfico 2 - Como é o uso das informações das (os) discentes

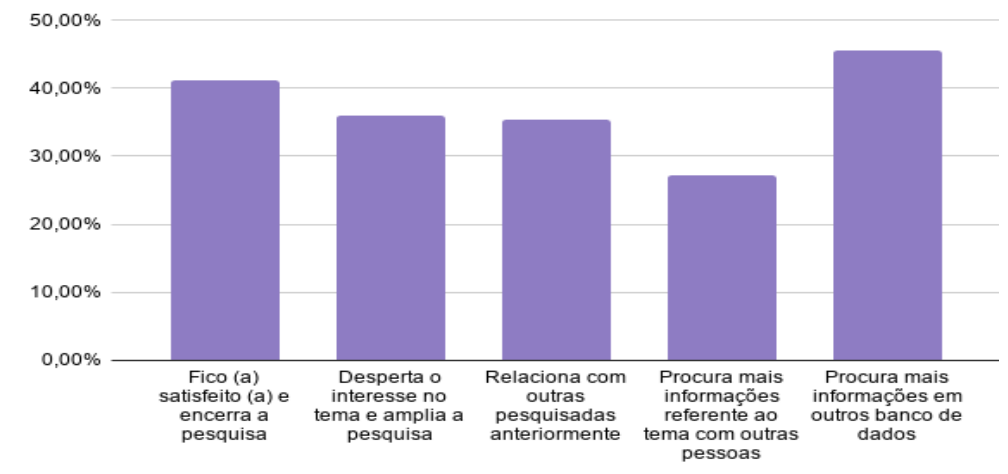

Fonte: Dados da pesquisa (2019). 
Constatamos que $41,2 \%$ das (os) respondentes ficam satisfeitas (os) e encerram suas pesquisas; $36 \%$ despertam o interesse quando realizam a busca e ampliam suas pesquisas; $35,3 \%$ relacionam outras pesquisas realizadas anteriormente com a atual; 27,2\% dos respondentes procuram mais informações referentes ao tema com outras pessoas; e 45,6\% procuram por mais informações em outros bancos de dados. Consonante Silva, Silva e Ramos (2016), o ato de pesquisar se dá a partir da busca pelo conhecimento. A maioria das respostas está relacionada às buscas pelas informações em diversos tipos de bancos de dados, mas ao mesmo tempo as informações recebidas despertam o interesse para ampliar o escopo da pesquisa inicial.

Há sujeitos que relacionam as pesquisas realizadas a outras feitas anteriormente, estabelecendo uma relação. Há também os que procuram por outras informações mediante as bases de dados, como o Google Acadêmico, Scielo e Portal Capes. Nesse sentido, os bancos de dados devem ser explorados com precisão, de forma a aprimorar e disseminar o conhecimento. Tendo essas informações coletadas, avançamos para a etapa das questões sobre as relações raciais, no âmbito da população negra.

Quanto ao estudo da temática racial, 58,1\% dos sujeitos respondentes alegam ter estudado, enquanto 41,9\% dos sujeitos alegam que não estudaram. A Lei 10.639/2003 torna obrigatório o ensino da História e Cultura Africana e Afro-brasileira em escolas públicas e particulares do Brasil, ressaltando a importância do povo negro na construção da sociedade e da economia brasileira. Gouvêa, Oliveira e Sales (2014) salientam que o surgimento da Lei 10.639/2003 tornou essencial a prática do ensino da Educação das relações étnico-raciais e do ensino de História e Cultura Africana nas escolas e nos cursos de graduação (bacharelado e licenciatura).

As lutas sociais da população negra no Brasil exemplificam as diferenças sociais que persistem por décadas desde a época da abolição dos atos escravocratas. O acesso a educação e a habitação tem sido cada dia mais limitante ao passo que há ainda a persistência de que não há exclusão social ou que não existe racismo no Brasil.

Em relação a possível necessidade de auxílio em pesquisas e buscas sobre a temática racial, 41,9\% dos respondentes costumam pedir ajuda; 35,5\% responderam que talvez possam pedir ajuda, dependendo da pesquisa; e 22,6\% responderam que não costumam pedir nenhum tipo de ajuda referente ao tema. Dependendo da qualidade dos recursos e serviços informacionais dispostos numa biblioteca ou qualquer outra unidade de informação, o processo de busca pode se realizar de maneira autônoma pelo sujeito. O (a) bibliotecário (a) 
trabalha na mediação constantemente e, caso haja a necessidade de auxílio à pesquisa, este (a) pode exercer diretamente o serviço de referência.

A temática racial - população negra tem em sua base um estudo denso e complexo, angariando diversas perspectivas e vivências alimentando bancos de dados com resultados amplos. Durante a análise das respostas, percebemos que nem todos conseguem realizar pesquisa referente ao tema. Essas podem e devem contribuir proporcionando conteúdos que favoreçam a visibilidade e as práticas antirracistas. O (a) bibliotecário (a) tem um papel determinante em tal situação, cooperando com a organização, tratamento e o acesso a tal informação e os (as) profissionais da informação e comunicação, em âmbito geral, podem cooperar com o tratamento, investigações de fluxo e disseminação de informação étnicoracial.

O Gráfico 3 determina quais são as fontes de informação mais utilizadas pelos sujeitos respondentes para buscas sobre a temática racial - população negra.

Gráfico 3 - Fontes de informação buscadas pelas (os) discentes para a temática racial

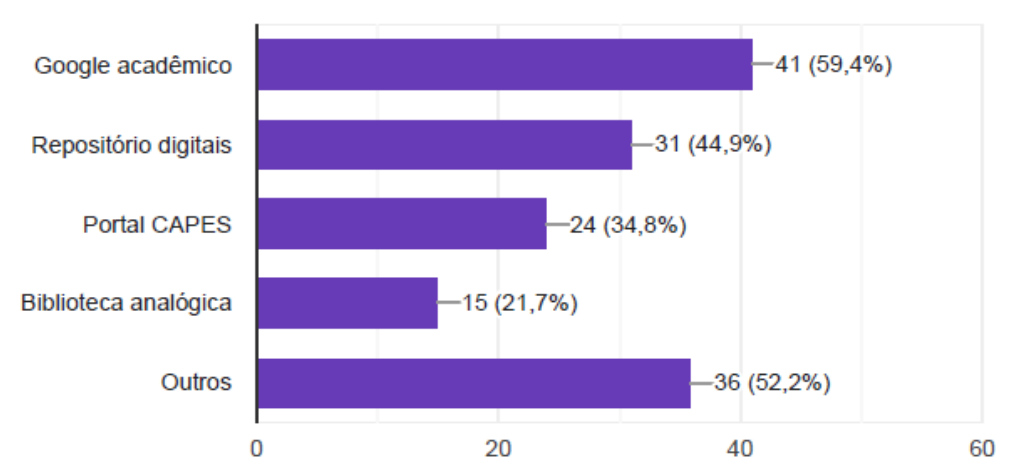

Fonte: Dados da pesquisa (2019).

Constatamos que as fontes de informação mais utilizadas são: Google acadêmico, utilizado por 59,4\% dos sujeitos respondentes; Repositórios digitais utilizado por 44,9\% dos sujeitos respondentes; Portal CAPES que totaliza 34,8\%; Biblioteca analógica, com 21,7\% de utilização pelos sujeitos respondentes; e 52,2\% utilizam outros tipos de fontes. O Google acadêmico recupera materiais informacionais diversos, como artigos de periódicos, livros, Trabalhos de Conclusão de Curso, Dissertações, Teses, publicações oriundas de eventos científicos, entre outros.

De acordo com o Gráfico 4, quando as (os) discentes encontram informações sobre a temática racial - população negra, 63,2\% discutem com outras pessoas; 47,8\% se aprofundam no tema com mais pesquisas; $39,7 \%$ buscam depoimentos de pessoas que sofreram algum tipo 
de preconceito ou racismo; e 4,4\% dos sujeitos respondentes pensam que o tema não tem tal relevância.

Gráfico 4 - O que a (o) discente leva em consideração quando encontra informações referentes à temática racial (população negra)?

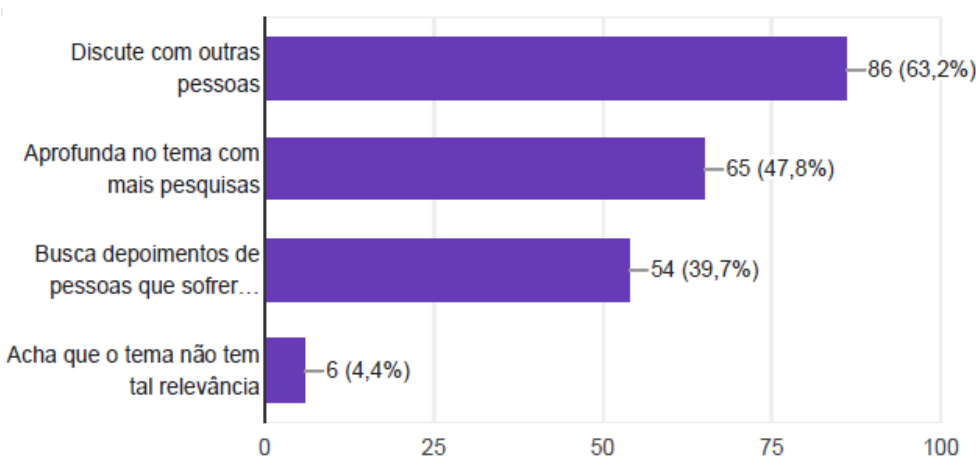

Fonte: Dados da pesquisa (2019).

As perguntas se deram através de questões que permitiam escolhas múltiplas, sem limitar quantidade, o que deixou os (as) discentes responderem conforme as suas práticas, não se limitando a apenas uma. O tema das relações raciais deve ser debatido e discutido dentro da Universidade, pois coopera com o conhecimento e com o crescimento social e intelectual.

Quanto a possibilidade de debate sobre a temática racial - população negra, o Gráfico 5 demonstra que $81,6 \%$ acreditam ser essencial debater o tema nas redes sociais; $89,7 \%$ determinam ser essencial discutir entre colegas, famílias e outros; 82,4\% pensam em ser essencial a fundamentação através de pesquisas e artigos científicos. Do mesmo modo, 79,4\% discentes pensam em ser necessária a discussão através de aulas referentes ao tema; e 32,4\% marcaram a opção "Outros”. Na pergunta, os sujeitos puderam assinalar mais de uma opção e a questão não teve obrigatoriedade de resposta.

Gráfico 5 - Sobre o debate referente à temática racial

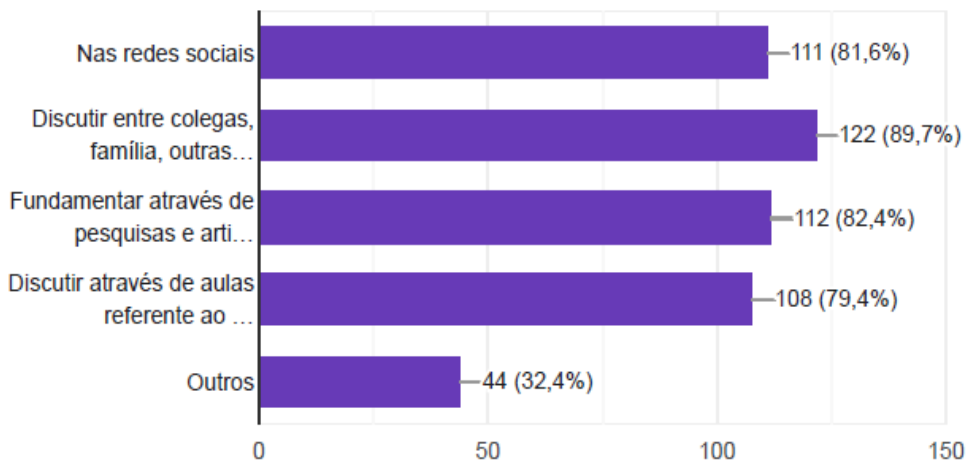

Fonte: Dados da pesquisa (2019). 
Constatamos a pertinência e a necessidade em se debater nas redes sociais, entre amigos (as), colegas e familiares, fundamentar através de pesquisas e estudar através de disciplinas a temática racial - população negra, especificamente a História e Cultura Africana e Afro-brasileira no contexto educacional refletindo na construção de uma sociedade antirracista, diminuindo a desigualdade racial.

\subsection{BLOCO 2: ANÁLISE DAS PERGUNTAS ABERTAS}

Neste segundo bloco, apresentamos as questões abertas. No âmbito deste artigo, é selecionado algumas respostas analisadas previamente e indicadas a seguir.

Para o primeiro questionamento "Você considera pertinente o debate sobre a temática racial (População negra)? Por quê?", sinalizamos três respostas positivas:

- "Sim, por conta da ampla carga histórica que levou ao desenvolvimento das dinâmicas sociais presentes na sociedade atual, que precisam ser compreendidas para ser mudado";

- "Com certeza, uma vez que é eminente o preconceito enraizado até nos mínimos detalhes da sociedade, é preciso mudar o pensamento social para que haja realmente não só representatividade como atuação por igual da população negra no mundo";

- 'Sim, visto que o preconceito racial ainda é muito presente no cotidiano dessas pessoas, é necessário se posicionar diante de atos criminosos como estes".

Ainda em relação ao primeiro questionamento, sinalizamos três respostas negativas:

- "Não. Artigo $2^{a}$ da Constituição Federal". (em refrência a "Todos são iguais perante a lei, sem distinção de qualquer natureza, garantindo-se aos brasileiros e aos estrangeiros residentes no País a inviolabilidade do direito à vida, à liberdade, à igualdade, à segurança e à propriedade" (BRASIL, 1988);

- "Não, acho que já passou da hora de evoluirmos e sermos apenas seres humanos e prontos";

- "Não, tal questão serve apenas para fomentar ainda mais a divisão entre os indivíduos. Somos todos humanos, alguns com tom de pele mais clara, outros com tom de pele mais escura".

Destacamos que é essencial discutir as temáticas raciais para acabar com as desigualdades raciais. Mesmo que haja um regimento jurídico que determine que todos são iguais, não é deste modo que acontece no país. A luta deve ser constante e os debates têm que ocorrer para disseminar informação referente ao tema, principalmente no que diz respeito à formação de profissionais da área de informação e comunicação. Dar visibilidade a população 
negra não é contribuir com a divisão entre raças, e sim, empregar o respeito trabalhando as diferenças existentes entre culturas e valorizando essa população historicamente discriminada. Para o segundo questionamento "Como futura (o) profissional na área da informação e comunicação, o que você faria para combater o racismo?", sinalizamos três respostas positivas:

- "A partir do meu trabalho, disseminando informações que possam fazer com que os indivíduos compreendem a perversidade do racismo e da discriminação, e possa travar a luta junta a população negra por uma sociedade antirracista";

- "Creio que rodas de conversas, trazer palestrantes negros para discutir o racismo. Lógico que sempre com cuidado para que não haja o preconceito reverso. Mas precisamos combater o racismo e empoderar a população negra";

- Primeiramente uma construção de um discurso sólido que seja calcado em fortes evidências e constatações científicas testadas e comprovadas para erradicar qualquer possibilidade de utilização de falácias. Utilizando dos aparatos legais para punir e conscientizar e, sobretudo não abrindo espaço, brecha para comportamentos inadequados, ilegais e nocivos sobre racismo".

Ainda em relação ao segundo questionamento, sinalizamos a única resposta negativa que se obteve:

- "Em minha opinião deveríamos discutir a sociedade como um todo, principalmente discutir o respeito. Só assim as diferenças seriam esquecidas. Pra mim o fato de fragmentar pessoas ou grupos faz com que o preconceito em todas as faixas só aumente”.

Debater a temática racial é primordial para o enfrentamento do racismo. Houve muitas respostas concordando com o debate em questão, para que haja igualdade, analisando os problemas que podem acarretar com o sujeito que sofre o racismo. A sociedade tem que reconhecer o racismo, entender as diferenças entre os preconceitos, quais são os direitos e quais fatores acarretam a não aceitação do que não é estabelecido como padrão. Portanto, acessar informações corretas sobre a população negra é um dos caminhos para o combate ao racismo.

\section{CONSIDERAÇÕES FINAIS}

A competência em informação é a habilidade que o sujeito adquire para buscar, avaliar e utilizar informação de qualidade. Com a tecnologia avançando, é necessário que o sujeito 
garanta habilidades para manusear ferramentas e os meios de acesso à informação. Por meio da aplicação do questionário, atingimos nosso objetivo ao analisarmos a competência em informação no campo das relações raciais, com foco na população negra, dos (as) estudantes da FIC/UFG.

A partir dos resultados constatados, devem ser pensadas estratégias dentro das Universidades, como ações e projetos que colaborem com a prática da igualdade racial para que os (as) futuros (as) profissionais da informação e comunicação se tornem competentes em informação nesse contexto. Pensamos que a criação de disciplinas obrigatórias que discutam as relações raciais nos cursos vinculados a FIC/UFG pode ser um dos caminhos que fomentem essas habilidades informacionais. Um fator essencial é mediar práticas de competência em informação dos (as) usuários (as) da biblioteca, de maneira que esse ambiente possa oferecer projetos como: leitura, cinema, roda de conversa, contação de histórias, entre outras propostas com autores (as) negros (as), engajando a representatividade.

Para que haja melhorias na busca da informação e na criação de uma sociedade livre de racismo, discriminação e preconceito, é indispensável a aplicação das Leis específicas existentes para as questões das relações raciais, cobrando direitos e exigindo a representatividade em instituições e organizações. Assim, a prática de mediação da informação antirracista é uma ação que contribui para a possível igualdade racial, sendo, portanto, um dos papéis a serem realizados pelo profissional de informação e comunicação. 


\section{REFERÊNCIAS}

ALMEIDA, Silvio. O que é racismo estrutural?. Belo Horizonte: Letramento, 2018. 204 p.

ARAUJO, Nelma Camêlo; FACHIN, Juliana. Evolução das fontes de informação. Biblos: Revista do Instituto de Ciências Humanas e da Informação, Rio Grande, v. 29, n. 1, p.81-96, 2015.

BASTOS, Rejane de. Análise do serviço de referência das bibliotecas universitárias do sistema de bibliotecas da UFRGS: a percepção do bibliotecário. 2013. 80 f. TCC (Graduação) - Curso de Biblioteconomia, Universidade Federal do Rio Grande do Sul, Porto Alegre, 2013.

BRASIL. Constituição (1988). Constituição Federal nº 2, de 1988. Constituição da república federativa do Brasil de 1988. Dos princípios Fundamentais: Brasília, BR, 05 out. 1988.

BRASIL. Lei no 10.639, de 9 de Janeiro de 2003. Brasília, 10 jan. 2003.

GASQUE, Kelley Cristine Gonçalves Dias. Arcabouço conceitual do letramento informacional. Ci. Inf., Brasília, v. 39, n. 3, p.83-92, jul. 2010.

GIL, Antônio Carlos. Métodos e técnicas de pesquisa social. São Paulo: Atlas, 2008.

GOUVÊA, Fernando César Ferreira; OLIVEIRA, Luiz Fernandes de; SALES, Sandra Regina (Org.). Educação e Relações Étnico-Raciais: entre diálogos contemporâneos e políticas públicas. Brasília: CAPES, 2014. 208 p.

GUIMARÃES, Antonio Sérgio Alfredo. Cor e raça: raça, cor e outros conceitos analíticos. In: PINHO, Osmundo Araújo; SANSONE, Livio (Org.). Raça: novas perspectivas antropológicas. Salvador: EDUFBA, 2008. p. 63-82

MUNANGA, Kabengele. Uma abordagem conceitual das noções de raça, racismo, identidade e etnia. In: Seminário nacional Relações raciais e educação-PENESB. Rio de Janeiro, 2003.

Anais... Rio de Janeiro, 2003.

PAIXÃO, Marcelo; CARVANO, Luiz M. Censo e Demografia: A variável cor ou raça nos interior dos sistemas censitários brasileiros. In: PINHO, Osmundo Araújo; SANSONE, Livio (Org.). Raça: novas perspectivas antroplógicas. 2. ed. Salvador: Associação Brasileira de Antropologia, 2008. p. 25-61.

PERES, Mônica Regina. Competência informacional: educação e sociedade. Rici: R. Iberoamericana, Brasília, v. 3, n. 1, p.22-33, jan. 2011.

PIRES, Erik André de Nazaré. Comportamento informacional e processo de busca da informação: bases fundamentais para pesquisa científica. Revista Acb: Biblioteconomia em Santa Catarina, Florianópolis, v. 17, n. 2, p.288-307, jul. 2012.

PRODANOV, Cleber Cristiano; FREITAS, Ernani Cesar de. Metodologia do trabalho científico: métodos e técnicas da pesquisa e do trabalho acadêmico. 2. ed. Rio Grande do Sul: Feevale, 2013. 
RIOS, Terezinha Azerêdo. Dimensões da competência. In: RIOS, Terezinha Azerêdo. Compreender e ensinar: por uma docência da melhor qualidade. 6. ed. São Paulo: Cortez, 2006. p. 93-109.

SILVA, Marília Felix da; SILVA, Júlio Pereira da; RAMOS, Carolina Soares. Pesquisa na formação acadêmica: aprender a pesquisar fazendo pesquisa. Conedu, São Paulo, v. [1], n. [1], p.1-11, nov. 2016.

SILVÉRIO, Valter R. Sons negros com ruídos brancos. In: In: SEYFERTH, Giralda et al. Racismo no Brasil. São Paulo: Peirópolis, 2002.

THEODORO, Mário et al. (Org.). As políticas públicas e a desigualdade racial no Brasil: 120 anos após a abolição. Brasília: Ipea, 2008. 180 p.

VALÉRIO, Erinaldo Dias; SILVA, Maria Feitosa da. Informar para a igualdade racial: participação cidadã na produção, acesso e uso da informação étnico-racial. In: SILVA, Franciéle Carneiro Garcês da; LIMA, Graziela dos Santos (Org.). Bibliotecári@s Negr@s: ação, pesquisa e atuação política. Florianópolis: Associação Catarinense de Bibliotecários, 2018. p. 179-196.

VITORINO, Elizete Vieira; PIANTOLA, Daniela. Dimensões da competência informacional. Ciência da Informação, Brasília, v. 40, n. 1, p.99-110, jan. 2011.

WILSON, Thomas D. Human Information Behavior. Information Science, v.3, n.2, p. 49-55, 2000 .

ZATTAR, Marianna. Competência em informação e desinformação: critérios de avaliação do conteúdo das fontes de informação | Information literacy and disinformation. Liinc em Revista, [s.1.], v. 13, n. 2, p.285-293, 1 dez. 2017. 